Proceedings

\title{
Autonomy, Testimony and Informational Diversity ${ }^{\dagger}$
}

\author{
Raffaela Giovagnoli \\ Faculty of Philosophy, Pontifical Lateran University, Vatican City 00120, Italy; giovagnoli@pul.it or \\ raffa.giovagnoli@tiscali.it; Tel.: +39-345-7963851 \\ † Presented at the IS4SI 2017 Summit DIGITALISATION FOR A SUSTAINABLE SOCIETY, Gothenburg, \\ Sweden, 12-16 June 2017.
}

Published: 8 June 2017

\begin{abstract}
I'll follow a line of thought that suggests to intend "personal autonomy" in a social sense. The urgency to undertake this move arises because of the wide variety of informational sources we are exposed which influence our behavior. Social background represents the basis for autonomy; at the same time, interaction with others (real or virtual) enlarges the possibility for autonomous judgements. My attempt is to try to elucidate the connection between autonomy, knowledge by testimony and the exposition to informational diversity.
\end{abstract}

Keywords: autonomy; communicative action; background knowledge; testimony; informational diversity

\section{Introduction}

The notion of "personal autonomy" defines those philosophical views that prefer to intend autonomy not only in a "moral sense". Moreover, my discussion does not concern the classical debate on free will (determinism/indeterminism). There are several theories of personal autonomy, that suggest to overcome the "individualistic" views [1]. Nevertheless, they are "social" in different senses, which I'll briefly describe.

Some philosophers maintain that an autonomous person must show not only "procedural" but also "substantial" independence, which rightly requires the consideration of the social context in which an action can be judged as autonomous [2]. Procedural personal autonomy requires the fulfillment of conditions for rationally deciding and acting, ranging over a wide spectrum of individual idiosyncratic desires and volitions (Dworkin, Frankfurt, Ekstrom). Several authors try to add "historical" conditions which examine the process of the formation of judgment or decision to act (Fisher, Ravizza, Christman). Very interesting and powerful are the substantive theories, that in the individual variant start from the Kantian inheritance (Korsgaard, Hills, Wolf).

My argument focuses on substantive views which consider the social contexts as sources of norms which favor or diminish development and exercise of the capacity for personal autonomy. A further question concerns the influence of informational diversity in enlarging the field of judgment, hence autonomy.

\section{Social Coceptions of Autonomy and Testimony}

The Habermasian account of "communicative action" represents a good model to relate autonomy to a linguistic normative competence. According to Habermas, autonomy is bound to the acknowledgment of presuppositions or linguistic rules as conditions of universal validity of theoretical and practical claims. Differently from other theories of "recognition", he plausibly introduced the issue of "interpersonal recognition" related to formal linguistic conditions of a rational and egalitarian dialog [3]. Habermas account of the relationship between autonomy and socialization is convincing because it shows plausible arguments against the contemporary 
reductionist strategies. Autonomy is directly bound to the notion of "communicative action", which, differently from instrumental and strategic action, aims at a rational consent. It is not only a question of an ideal point of view under procedural conditions (introduced from an external perspective), rather the development of the possibility for autonomy through communicative action is based on a wellknown process of socialization explained also by reference to different disciplines (Piaget, Kohlberg).

Procedural theories underestimate the role of the internalization of oppressive norms; from a substantive point of view, even if a person has to some extent the option of choosing alternative values, it is the content of the norms she internalized that diminishes her autonomy. We must consider the nature of values that come from the social context (Stolyar, Benson, Oshana among others). Several relevant authors in the field of social epistemology think that the model for an ideal knower must be abandoned (see Hardwig, Welbourne, Schmitt, Baier, Webb, Goldman, Jones, Fricker Faulkner, Lipton, Kusch, Lackey) [4]. These authors generally think that we cannot neglect ethical and social dimensions of inquiry. A strong view among social epistemologists is that an individual cannot be said to know, via testimony, that $p$, unless $p$ is known in the community (see Welbourne, Brandom, Faulkner). In Brandom's account of "recognition" in scorekeeping terms the possibility to undertake an autonomous perspective is bound to "deontic attitudes" and "deontic statuses". Recognition seems a fundamental requirement for an agent to be autonomous, but reciprocal recognition is possible by virtue of "shared commitments" [5].

The result is that autonomy is not thinkable without shared knowledge and testimony is a fundamental source of knowledge. An interesting observation simply suggests that an epistemic agent whose beliefs does not depend upon testimonial transmission knows very little. So, we must consider our limitations and our need to economize. If we do not ignore these, autonomy will appear irrational for accepting a huge loss of information, ignoring how we exploit a division of epistemic labor (Putnam, Kitcher, Owens).

\section{Informational Diversity}

A recent article on the positive effects of informational diversity "indirectly" shows arguments that support also the possibility of developing more autonomy when we are exposed to a wide variety of information which stimulate our thought [6]. Decades of research by organizational scientists, psychologists, sociologists, economists and demographers show that socially diverse groups (that is, those with a diversity of race, ethnicity, gender and sexual orientation) are more innovative than homogeneous groups. A very interesting observation is that it seems obvious that a group of people with diverse individual expertise would be better than a homogeneous group at solving complex, non-routine problems but it is less obvious that social diversity should work in the same way (the science shows that it does). It is not a question about the misure of information coming from different individuals; interaction among different individuals forces group members to prepare better, to anticipate alternative viewpoints and to consider the difficulties to reach the consent. The main notion to understand the positive influence of diversity is "informational diversity". When people interact to solve problems in groups, they bring different information, opinions and perspectives.

This is clear if we think to some forms of Collective Intentionality in John Searle's sense. We have different parts and expertise in working as an interdisciplinary team (for instance building a car). Social diversity works the same way (Deszö, Ross, Richard). Research on racial diversity in small group does not only show the correlation between diversity and better performances; it shows that diversity causes better performances. The results are clear: for groups that value innovation and new ideas, diversity helps (Neale, Northcraft, Lising Loyd, Wang, Freeman).

\section{Conclusions}

We can observe the logic that clarifies the dimensions of social diversity: people work harder in diverse environments both cognitively and socially. Consequently, this hard work can lead to better outcomes (Sommers). From a philosophical point of view, my option can use the results of the research on social diversity to ground a notion of autonomy that overcomes procedural theories and 
tries to understand the role of the content for autonomous agency. Because of the participation in the game of giving and asking for reason, where we are exposed to different perspectives, we are motivated to cooperate and so we can master the communicative structure of justification by "default" and "challenge". Autonomy is relational in two senses: (1) the "semantic" sense that shows the inferential shared commitments (governed by material incompatibility) agents must acknowledge and (2) the "pragmatic" sense that reveals the normative structure of that acknowledgment as a social net of deontic attitudes.

Conflicts of Interest: The authors declare no conflict of interest.

\section{References}

1. Giovagnoli, R. Autonomy. A Matter of Content, 1st ed.; Firenze University Press: Florence, Italy, 2007.

2. Giovagnoli, R. Computational aspects of autonomous discursive practices. In Proceedings of the AISB Conference, University of Kent, Canterbury, UK, 20-22 April 2015.

3. Giovagnoli, R. A Social Notion of Autonomy. In Proceedings of the AISB Conference, University of Sheffield, Sheffield, UK, 4-6 April 2016.

4. Giovagnoli, R.; Formanova, J. Autonomy and Social Attitudes. In Proceedings of the AISB Conference, University of Bach, Bath, UK, 18-22 April 2017.

5. Christman, J.; Anderson, J. (Eds.) Autonomy and the Challenges to Liberalism, 1st ed.; Taylor, J.S. (Ed.) Personal Autonomy, 1st ed.; Cambridge University Press: Cambridge, MA, USA, 2005.

6. Habermas, J. Nachmetaphysisches Denken, 1st ed.; Suhrkamp Verlag: Frankfurt am Main, Germany, 1991.

7. Adler, J. Epistemological Problems of Testimony, 2nd ed.; Stanford Enciclopedia od Philosophy. Available online: https://plato.stanford.edu/entries/testimony-episprob/ (accessed on 27 August 2012).

8. Brandon, R. Autonomy, Community and Freedom. In Autonomy of Reason? Autonomie der Vernunft?, 1st ed.; Dottori R., Ed.; LIT Verlag: Berlin-Wien, Germany, 2009; pp. 166-178.

9. Phillips, K.W. How Diversity Makes Us Smarter. Sci. Am. 2017, 311, 1. Available online: https://www.scientificamerican.com/article/how-diversity-makes-us-smarter/ (accessed on 30 January 2017).

(C) 2017 by the authors. Licensee MDPI, Basel, Switzerland. This article is an open access article distributed under the terms and conditions of the Creative Commons Attribution (CC BY) license (http://creativecommons.org/licenses/by/4.0/). 